Hoda Natasha,

$\mathrm{MsC}, \mathrm{PhD}$ Candidate, Agriculture University of Tirana, Faculty of Economy and Agro-business, Tirana, Albania

E-mail:natashahoda@yahoo.com

Hoda Hysen,

Doc. Dr., "Aleksandër Moisiu" University, Faculty of Business, Durrës, Albania E-mail:hhodaj@yahoo.com

Forcim Kola, Dr., "Aleksandër Moisiu" University, Faculty of Business, Durrës, Albania E-mail:forcimkola@gmail.com

\title{
Microfinance market and social media marketing
}

Abstract: Electronic marketing and especially the rise of social media marketing, has made Microfinance Institutions (MFIs)to have the opportunity to talk to thousands of customers, send out messages, get fast feedback, and experiment with offers at relatively low costs. Social media is perceived by consumers as a more trustworthy source of information regarding products and services than business-sponsored communications transmitted via the traditional elements of the promotion mix.

Social media channels help MFIs to communicate and organize themselves together, and allow them to reach out and relay their messages to a larger group of people in order to create awareness and promote brand.

The aim of this paper is to investigate at what extent social media platforms are being used by microfinance institution as a communication tool with their clients and to identify how organization engaged in social media efforts are expanding their opportunity in reaching their target market. This study also tries to measure the effectiveness of social media marketing in the development of microfinance sector in Albania.

The methodology used includes a structured questionnaire developed to collect the required primary data from MFIs operating in Albania, which were distributed and filled out. The data were analyzed and presented in the respective results and findings.

Keywords: Microfinance market, social media marketing, customer attractiveness.

\section{Introduction}

Web technologies have transformed the way people live and work by making it easier to connect and engage online. They have also enabled major changes in customer behavior which in turn have revolutionized industries that have successfully incorporated these technologies in their business model.

The evolution of communication technology in recent years has facilitated business's ability to network with its existing and potential customers. What once required face-to-face conversations and the physical exchange of contact information can now be done in an entirely virtual environment with just a click of a button.

In the new era of advances in communication technology, it is no wonder, then, that the micro financial services industry is beginning to use various forms of Computer Mediated Communication (CMC) to enhance customer service and improve current products and services. The most popular form of CMC are social networking websites such as Twitter, Facebook, MySpace, and LinkedIn, which are used primarily to maintain or build connections among users.

Whether educating customers on new services, boosting customer confidence, increasing sales outreach or personally connecting with their customers to meet their lending needs - social networking is a vital communication tool that MFIs can utilize in many of their customer business interactions [22].

This paper is organized as follows. First, is offered an overview of social networking and its characteristics related to microfinance institutions and then is presented the methodology and the research conducted for the purpose of the study. Major findings and result are also explained and interpreted. In the end we provide a set of conclusion and recommendation.

\section{Social Media Marketing and MFIs}

Microfinance Institutions (MFIs) provide loans to small and medium enterprises who often can't meet the strict credit terms of formal banking. Either these entrepreneurs don't have the capital or the cash to pay 
back the loan. Or as the large banks argue, their credit needs are too small.

With banks out of the picture, micro lending agencies step into the role usually held by the imperfect combination of relatives and often predatory money lenders. Microfinance programs extend small loans to poor people for their varied needs such as consumption, shelter, income generation and self-employment. In recent years, microfinance has gained growing recognition as an effective tool in improving the quality of life and living standards of poor people.

As the internet age hit, micro lenders began looking for ways to promote their activity. The rise of social networking has enabled most of MFIs to easily interact with customer, to get fast feedback and most importantly to explore their lending needs.

The symbiotic relationship between MFIs and social media works two ways. First, it helps MFIs to communicate and organize themselves together. It makes sharing of information within the industry and easier. Also it keeps MFIs updated with what other institutions are doing. Second, it allows MFIs to reach out and relay its message to a larger group of people in order to create awareness and promote brand.

Before exploring how the social network can impact a MFI activity, it would be appropriate to briefly define and understand social media marketing. Social media is also referred to as consumer-generated media. This form of media describes "a variety of new sources of online information that are created, initiated, circulated and used by consumers intent on educating each other about products, brands, services, personalities, and issues".

Social media encompasses a wide range of online, word-of-mouth forums including blogs, company sponsored discussion boards and chat rooms, consumer-toconsumer e-mail, consumer product or service ratings websites and forums, internet discussion boards and forums, mob logs (sites containing digital audio, images, movies, or photographs), and social networking websites, to name a few [18].

Social networks, the term commonly used as the shorthand for social networking services, refers to a wide variety of internet offerings that are quite different from one another. At the most basic level, social networks share three features:

1) Persistent online profiles: User presence, typically visible via a profile or collection of content and comments. Social networks enable users to present themselves to the world.
2) Linking among profiles: Networks need the ability to link between users and make connections, thus creating a networked ecosystem of nodes. Social networks allow users to interact with each other in a variety of ways, whether via email, instant messaging (IM), chat, publicly posted messages, or voice and video interaction.

3) Interactive functionality: Social networks offer functionality that enables interaction between users, which also adds richness and informs the community about the user [14].

Online social networking offers many of the same benefits as traditional networking, while allowing micro lenders to more easily network with the average consumer as well as with their colleagues in the financial industry.

Used appropriately, online social networking offers businesses the opportunity to develop meaningful, longlasting customer relationships. Here are the different types of social media channels:

- Social-media sharing services: These media channels facilitate posting and commenting on videos, photos, and podcasts (audio):

a) Video sharing sites (YouTube);

b) Photo sharing sites (Flickr);

c) Music sharing sites (Jamendo.com);

d) Content sharing combined with assistance (Piczo.com).

- Blogs: Web sites designed to let you easily update or change content and allow readers to post their own opinions or reactions such as WordPress, TypePad, and Blogger (formerly Blogspot).

- Social bookmarking services allowing users to recommend online news stories, music, videos. Similar to private bookmarks for your favourite sites on your computer, social bookmarks are publicly viewable lists of sites that others have recommended.

a) Recommendation services such as Delicious;

b) Social shopping services such as Kaboodle or ThisNext;

c) Other bookmarking services organized by topic or application, such as book recommendation sites.

- Social networking sites (MySpace, Facebook, Faceparty).

- Business/professional networking sites (LinkedIn, Plaxo).

- Collaborative websites (Wikipedia) [24].

The decision to embrace social media technology is a risk-based decision, not a technology-based decision. It must be made based on a strong business case, supported 
at the appropriate level for each department or agency, considering its mission space, threats, technical capabilities and potential benefits.

\section{Study purpose and methodology}

This study explores MFI's relationships with social media websites and tries to investigate at what extent social media platforms are being used by microfinance institution as a communication tool with their clients and to identify how organization engaged in social media efforts are expanding their opportunity in reaching their target market.

Some key research question includes:

1) Have microfinance institutions sensed a changing landscape due to social networking?

2) What are the perceived and measured benefits of social media marketing?

3) Which social media sites MFIs are concentrating their efforts on?

4) Will social networking impact a MFIs overall expansion?

\section{Methodology}

In order to investigate our research questions, MFIs managers were interviewed on the basis of a questionnaire.
The aims were to: highlight the way in which managers perceive the phenomenon; recognize the activities developed by each MFIs and investigate the relation between social media activities and Microfinance Institutions.

A total of 150 questionnaires were distributed and filled out from MFIs operating in Albania. The survey was defined with the aim to involve the highest possible number of relevant social media marketing topics and give the issue a more wholesome perspective.

\section{Data analyses and study findings}

The use of social websites has become a part of many consumers' everyday lives. Social media is no longer a channel through which people simply chat, post videos or share photos.

It is a powerful marketing channel through which businesses and brands can connect with consumers on a relational level and help build a community of relationships.

When asked to rate their experience using social media marketing for their businesses, a significant $63 \%$ of MFIs managers have either just started or have been using social media for only a few month. But many still say social media is an experiment conducted by a few individuals in marketing or communications (Chart 1).

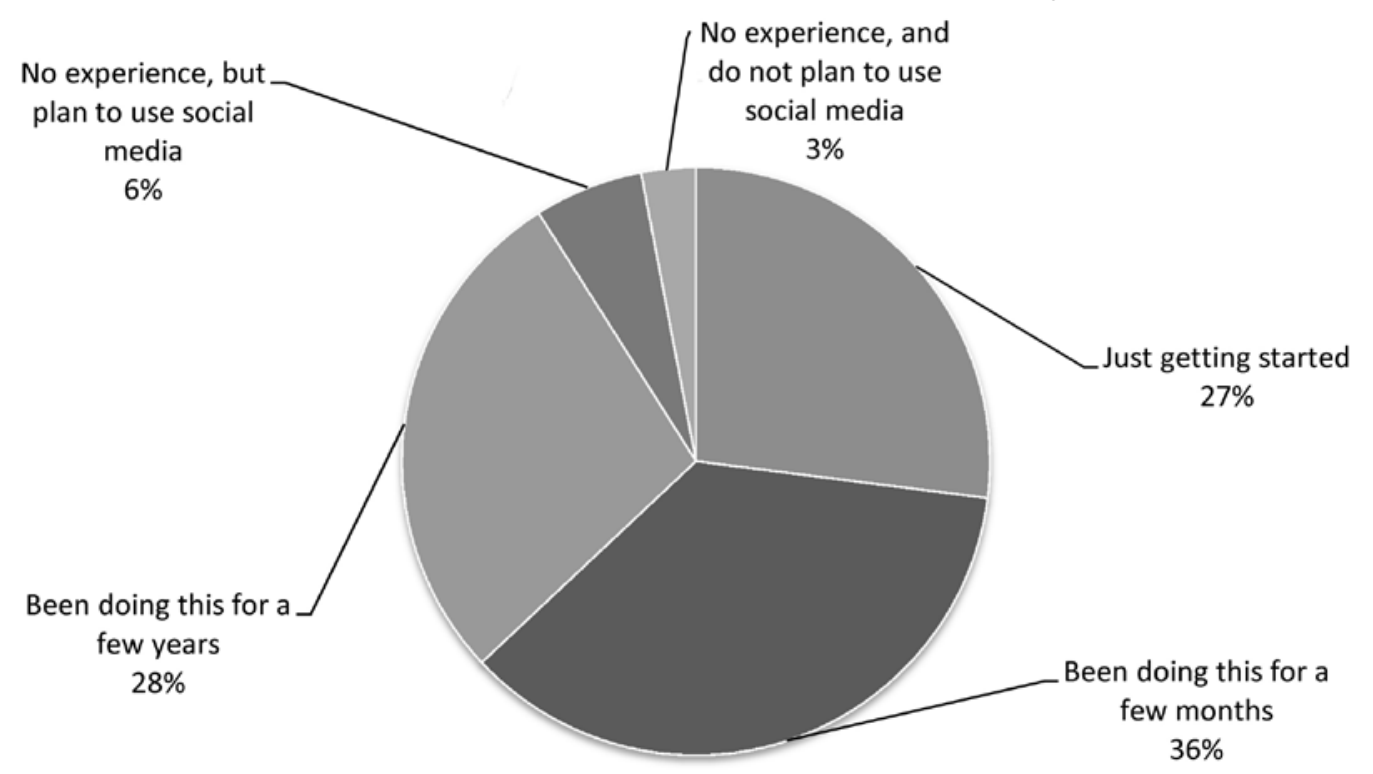

Chart 1. Experience with social media marketing [32]

Some said they perceive dangers in exposure and lack of control of the conversation on the Web. Only a small percent of the respondents said they do not use social media and have no plans to do so.

Among all MFIs, social networking sites that were the most popular form of social media were Twitter (87\%), LinkedIn (79\%), Blogs (71\%) and Facebook (78\%), as shown in Chart 2.

These were the top four social media tools used by marketers, with Twitter leading the pack. As it is showed in the following chart all the other social media tools paled in comparison to these top four.

Some microfinance institutions have expressed concern about connecting with customers via social networks because customers will have an avenue to communicate their own reviews or opinions alongside the social community. In reality, it is not true that a lack of engagement will protect or insulate the microfinance institution's brand - customers will talk online regardless of if the brand has an official presence. 


\section{Commonly social media tools used by microfinance companies}

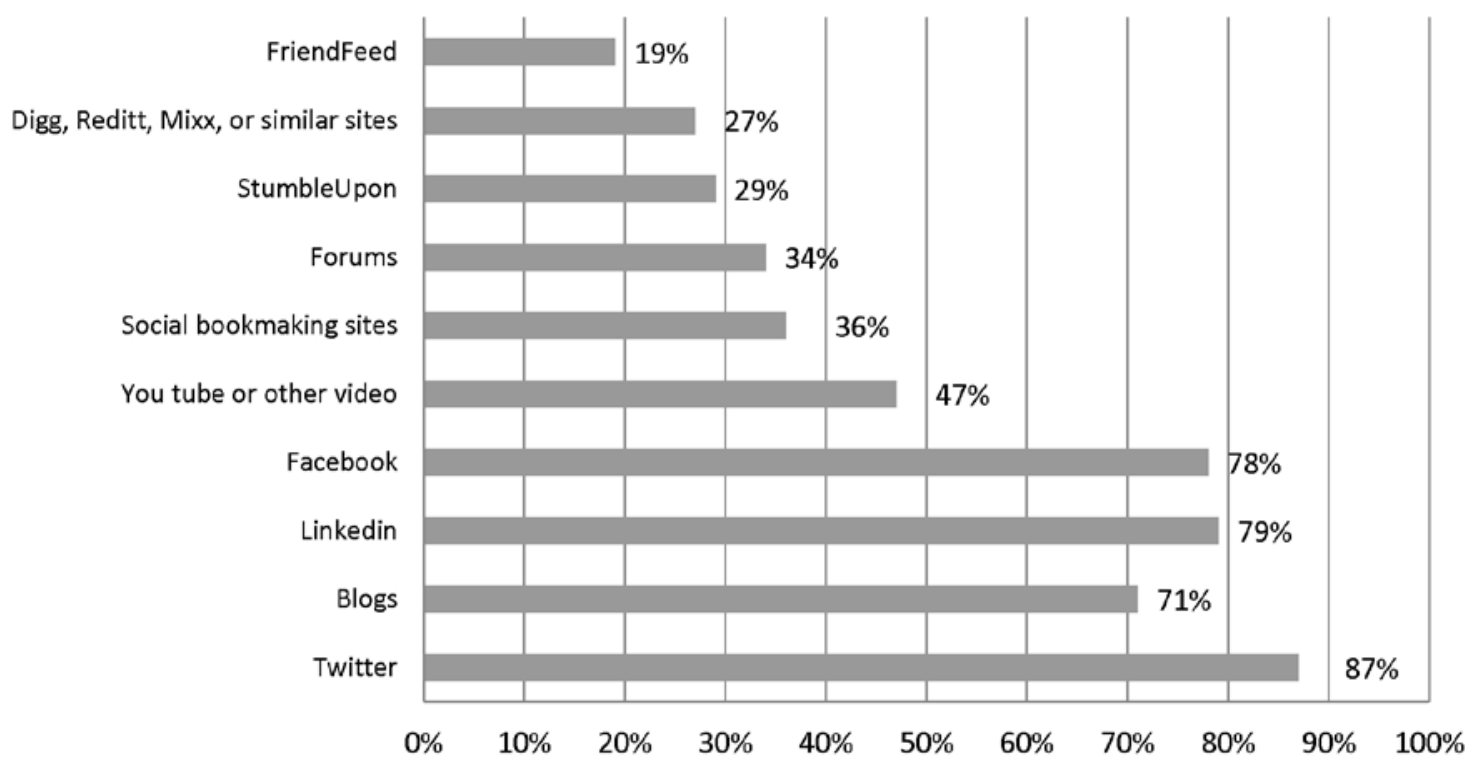

Chart 2. Current usage of social media channels [32]

Among institution currently using social media, in the survey half said the main benefit of their activity was increasing awareness of the organization and its products and services among target customers.

Twenty-seven percent said social media usage lead to more favorable perceptions of the organization, products, or services. Another $36 \%$ see an increase in traffic to their website as a prime benefit, but only $25 \%$ report collecting and tracking customer reviews on their website or other websites, as shown in Chart 3.
The majority of MFIs said social media did give them some ability to monitor what was being said, only $5 \%$ said that the ability to measure the frequency of discussion about the organization was a current benefit and only $15 \%$ said they were able to identify positive and negative comments.

In short, many organizations' activities seem more focused on "making noise" about their company and products, and less on understanding and participating in the conversations already going on about them on the Web.

\section{Primary benefits of microfinance companies using social media}

Early warning of potential product or service issues

Ability to measure the frequency of discussion about our organization

Have not derived any benefits at this point

Identification of new product or service opportunities

Increase in new business

Identification of positive/negative comments

Improved insights about our target market

Better understanding of customer perceptions of our brand

Development of targeted marketing activities

Ability to monitor what is being said about our organization

More favorable perceptions of our organization, products, or services

Increased traffic to website

Increased awareness of our organization, products, or services among...

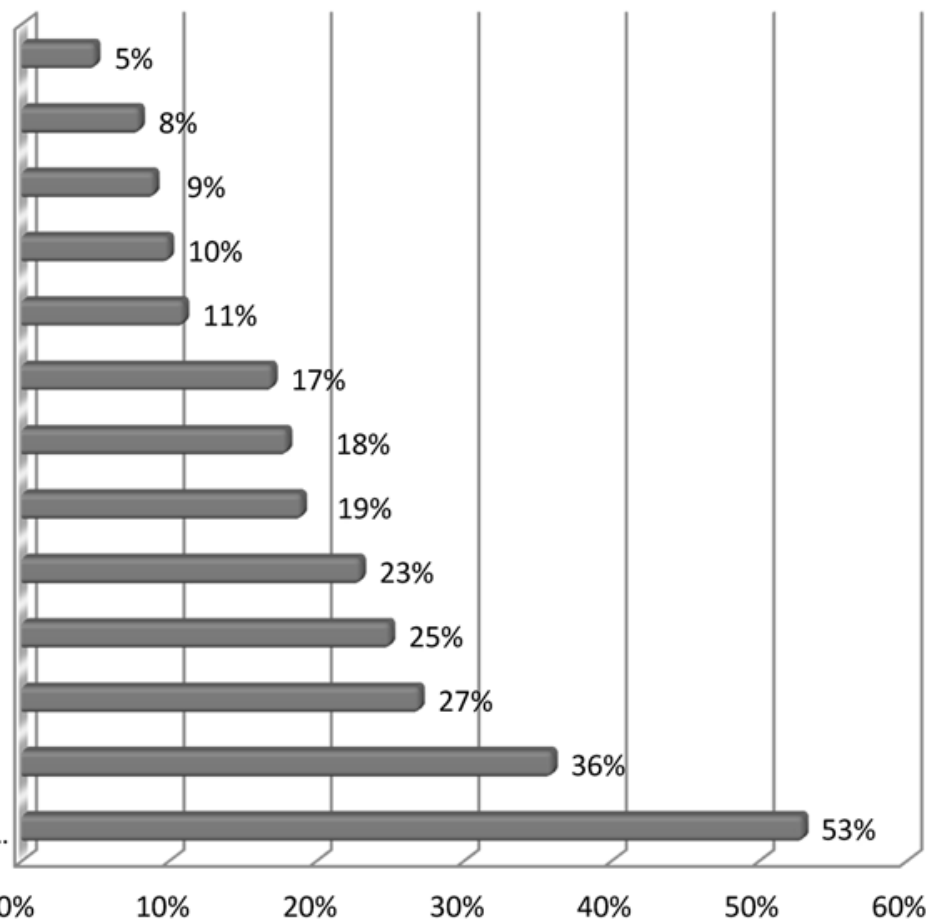

Chart 3. The benefits of social media marketing [32] 
Some questions that naturally emerge from the above chart might include, "Is there a way to improve the likelihood of achieving these benefits by investing more time in social media?" and "Are those marketers who've been doing social media marketing for years gaining even better results?".

The only financial cost of social media marketing is the time it takes to gain success. However, a significant percent of participants strongly agreed that overall marketing costs dropped when social media marketing was implemented.

Without monitoring conversations on the Web, you won't know who's talking about your brand and your products or services, and what the positive and negative sentiments are about them. You won't know how influential a particular praising or criticizing customer is. In short, you're missing a lot of marketing opportunity.

MFIs were asked to rate on a scale of 1 to 10 , how effectively do they feel their organization is currently using social media, where $1=$ not at all effectively and $10=$ extremely effectively.

In the survey, there was a small group of MFIs just $15 \%$ - who described themselves as effective users, as shown in Chart 4. This group comprised a kind of "best practices" segment. They were much more likely to be fully-leveraging the benefits of social media by using multiple social media channels to reach customers, learn about customers, research new products, and establish user groups among customers. This group was also far more likely than others to integrate their social media monitoring solution with their other marketing solutions.

Effective users are far more likely to use more social media channels - four or more - and much more likely to be doing more multi-media sharing, and participating in review sites, discussion forums, and blogs. Sixty-three percent of the effective users said they have developed and implemented a social media strategy.

For many microfinance companies, social media use is still viewed as an experiment, where discrete projects are launched, usually by a few individuals in marketing or communications. Some said they limit their activities because they are in a "test" mode and lack resources to do more. Others said the organizations are wary because they perceive dangers in exposure and lack of control of the conversation on the Web.

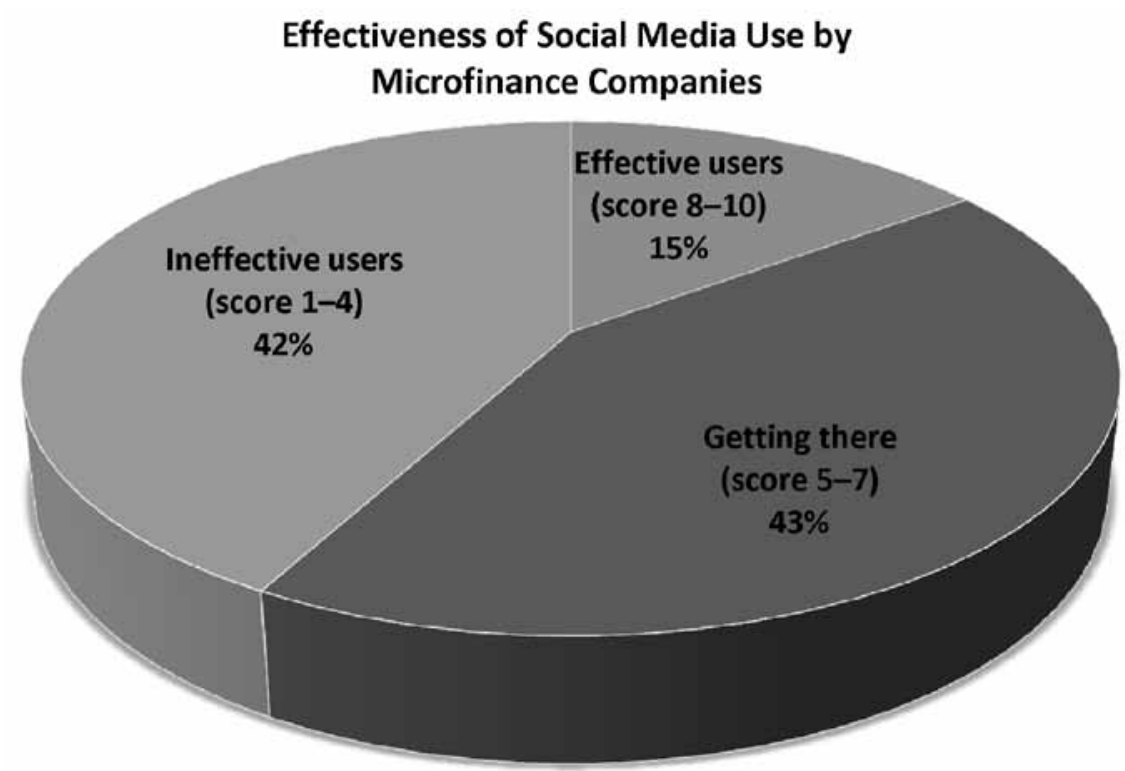

Chart 4. Effectiveness of social networking [32]

Within user organizations, the marketing department plays a key role with social media efforts most likely to be directed by the marketing department (78\%), followed by the communications, PR, and Web teams (Chart 5). Just $10 \%$ of social media users have a dedicated budget for their social media activities, with marketing controlling that budget in almost half the companies.

About a quarter of the users outsource some social media activities to public relations agencies or others. Only a handful of organizations ( $8 \%)$ have dedicated staffs who work only on social media: the rest said that social media is only "part of the job" for employees in areas like marketing, PR, and communications. Overall, a quarter $(26 \%)$ has up to one full-time equivalent working on social media.

This reflects just how experimental many organizations view social media and how they have been reluctant to commit resources, perhaps because they are still not certain of its goals, effectiveness, and impact on the organization. 


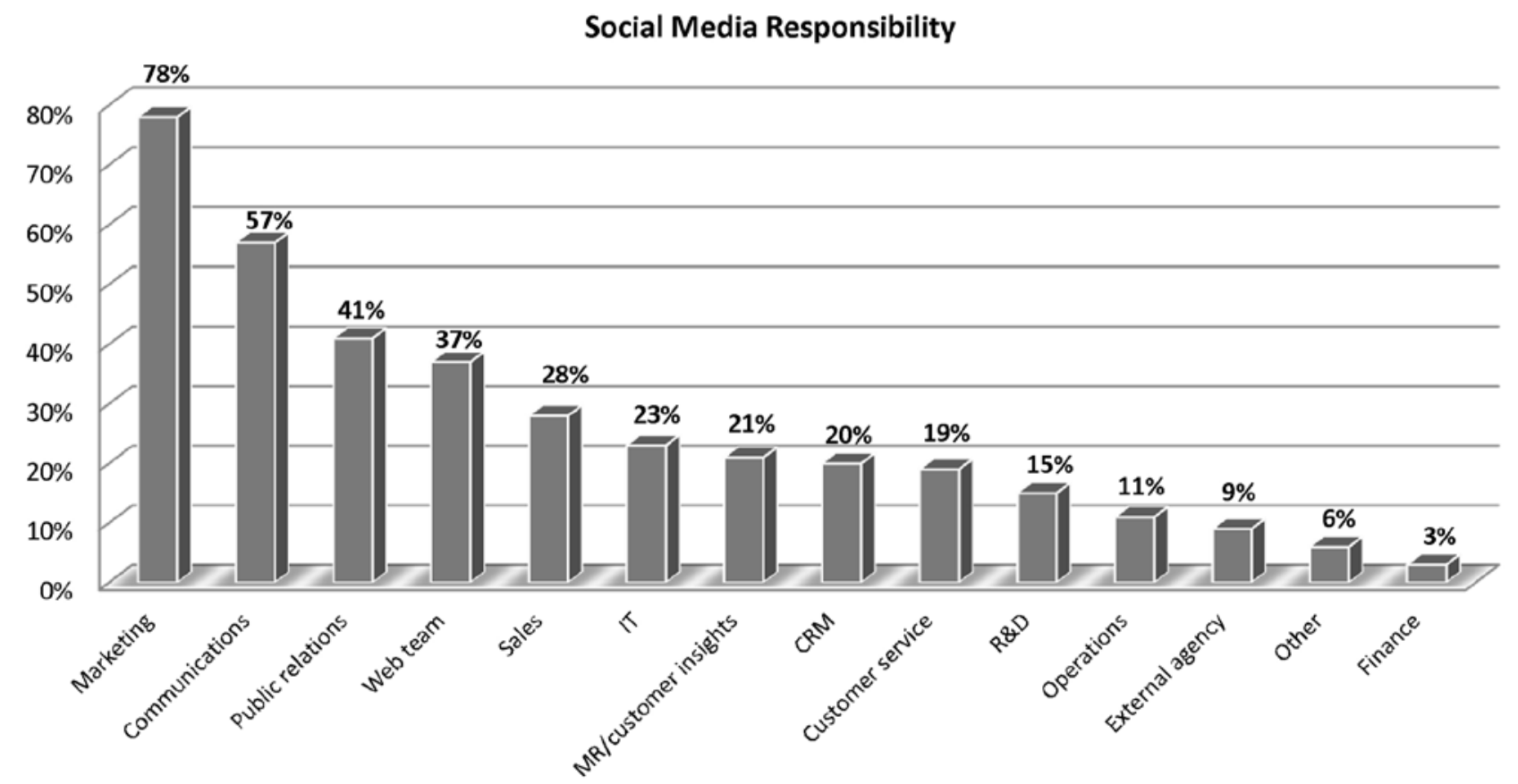

Chart 5. Responsible structure in developing social networking [32]

From the best experience worldwide one of the first micro lenders to have an impact over the internet is the US-based Kiva, which began a few years after a couple traveled to East Africa in 2004. Kiva claims to be the world's first "person-to-person micro-lending website".

In Kiva's website you can lend to someone across the globe who needs a loan for their business. Each loan has a picture of the entrepreneur, a description of their business and how they plan to use the loan so you know exactly how your money is being spent - and you get updates letting you know how the entrepreneur is going.
What helps drives these sites isn't just the loans; it's the methods used to make the funds available. Social networks are important. Trust - more commonly called social capital in this situation - is the strength and number of interpersonal connections. Facebook, Twitter, MySpace and the like are convenient ways to map out these connections (within a connected group of people), but hardly replace them.

Have Albanian's microfinance institutions comprehend and cope this new area of digital communities and what are the main activities they are developing to support this fast growing new medium?

\section{Type of Social Media Usage}

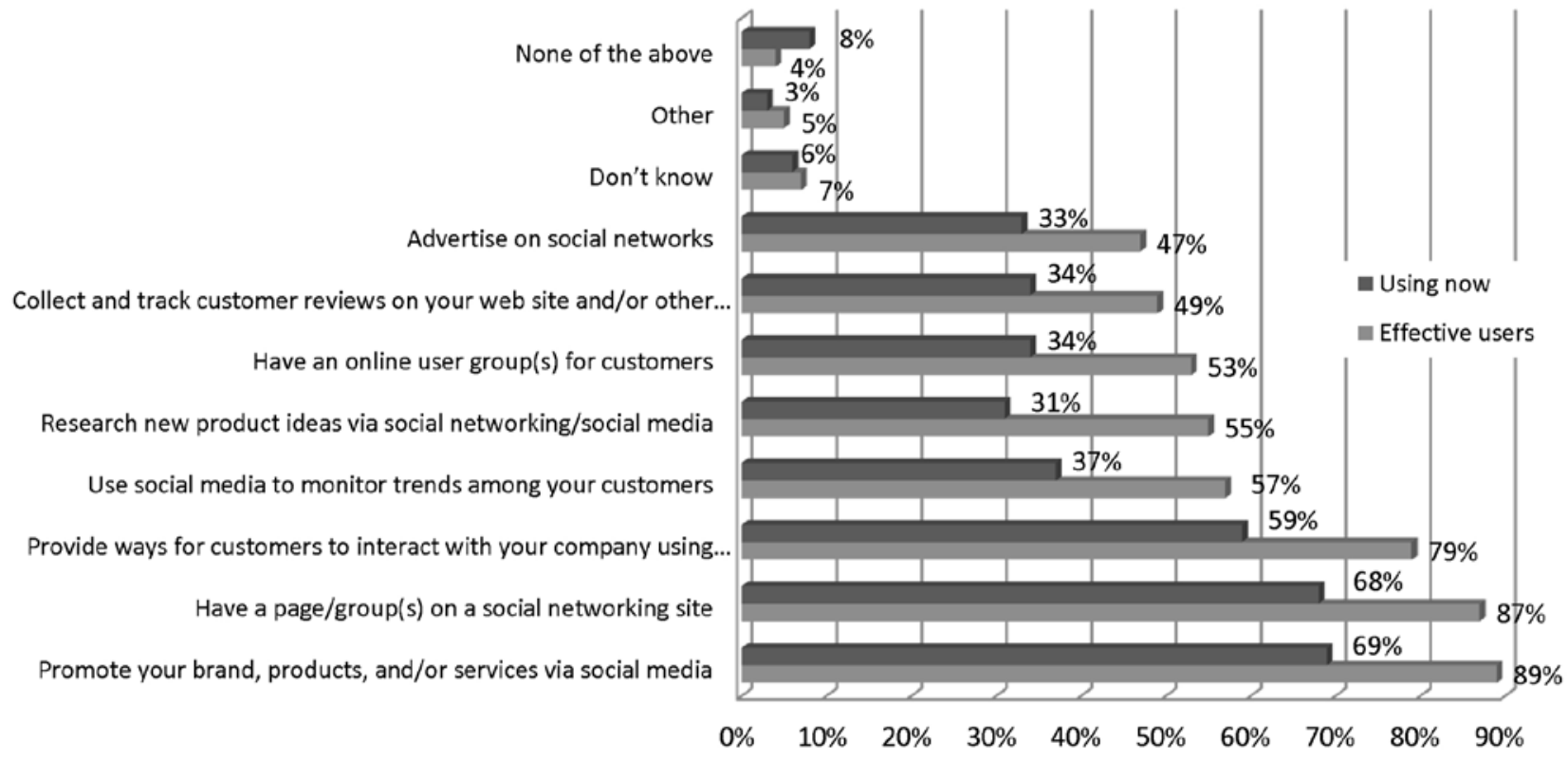

Chart 6. Types of social media activities [32] 
The chart below describes the main types of activities that are taking place among MFIs in Albania.

From the above chart, it can be summarized:

- Effective users are far more likely to use more social media channels - four or more - and much more likely to be doing more multi-media sharing, and participating in review sites, discussion forums, and blogs.

- Sixty-three percent of the effective users said they have developed and implemented a social media strategy.

- Effective users are more likely to use social media to monitor trends, research new product ideas via social networks, have an online user group for customers, and collect and track customer reviews on their website.

- Effective users are more likely to know where customers are talking about them on the Web and prioritize their social media activities accordingly. Out of all the executives in the survey, only one-quarter said they could target where their most important customer segments discussed their brands and services. That number rose to almost $70 \%$ among effective users.

\section{Conclusions}

Use of social media marketing will clearly expand in the next coming years. Two-thirds of the institutions in the survey predicted their use of social media marketing would grow significantly over the next few years, as the awareness of the power of social media has grown in their companies.

Microfinance institutions must consider the risks and rewards of using social marketing in their everyday business operations, and ensure that these tools conform to policies and legislation, while meeting the needs of their customers.

Because customers are the driving force for success in the financial services industry, the key to protecting them is through employee education. It is imperative that MFIs employees are appropriately trained before and during the use of any type of social networking tool.

Understanding how this new form of communication impacts the organization in the long-term can help a micro financial institution plan for and attain future success, while focusing on keeping customer relationships strong and information and financial assets secure as social networking becomes a more prominent business tool.

For microfinance institutions to maximize the opportunity that social media provide, we offers the following recommendations:

a) Embrace the Opportunity: Microfinance institutions should embrace the opportunity to form and enhance digital relationships through social media.

b) Increase Awareness: MFIs should incorporate social media messaging into existing marketing efforts in other channels. This can be as simple as incorporating Facebook or Twitter icons into print or digital marketing communications.

c) Differentiate Social Media from the TransactionDriven Website: The primary reasons for connecting with a brand are personal and relational. Microfinance institutions must differentiate the social media channel from the transactional channel and offer customers community-building activities, such as access to fellow customer recommendations, they cannot get from the traditional website.

d) Communicate a Clear Value Proposition: MFIs must clearly communicate and educate customers on the additional value of connecting through social media. Emphasizing the unique benefits of the channel such as the ability to interact with other customers, receive special offers, and contact customer service will help customers better understand why they should connect.

Consumers have embraced social media because it is engaging, fun and entertaining and they have demonstrated they are willing to connect with brands through the same channel in which they interact with friends, family and coworkers.

Now it's time for micro financial institutions to embrace social media. Leveraging social networks, MFIs can foster deeper, more personal relationships, resulting in more profitable and loyal customers.

\section{References:}

1. Abhijit V., Banerjee and Esther Duflo. Poor Economics. - New York: Public Affairs, 2011.

2. Addison Tony, Mavrotas George. Development Finance in the Global Economy. - The Road Ahead, 2008.

3. Ashta A. Advanced Technologies for Microfinance: Solutions and Challenges, Groupe ESC Dijon Bourgogne. France, 2011.

4. Belch G.E. and Belch M.A. Advertising and promotion: An integrated marketing communication perspective.McGraw-Hill/Irwin, Boston, 2003. 
5. Belegu K. Dissertation, "Microfinance Institutions and their Contribution on the Reduction of Poverty in Rural Albania”. - (AGR/01). - 2010.

6. Boone L. E. \& Kurtz D.L. Contemporary marketing (13 ${ }^{\text {th }}$ ed.). - Mason, OH: Thomson/South-Western, 2007.

7. Ceku Bardhyl, Kola Forcim. Metoda Kërkimi. - Tirane, 2011.

8. Ceku Bardhyl, Kola Forcim. Metoda të Kërkimit Shkencor. - Tirane, 2008.

9. CGAP, Microfinance Investment in Sub-Saharan Africa: Turning Opportunities into Reality. - June 2012.

10. Churchill G. A. A Paradigm for Developing Better Measures of Marketing Constructs.//Journal of Dozier, 1979.

11. Convergences 2015.org. Microfinance Barometer 2014, $4^{\text {th }}$ Edition. - October 2014.

12. Edwards Burt. Credit Management Handbook. Fifth edition. - 2004.

13. Fairchild M. Evaluation: An opportunity to raise the standing of PR.//Journal of Communication Management. - 2002. - Vol. 6(4), 305-307.

14. Halligan B. \& Shah D. H. Inbound Marketing: Get Found Using Google, Social Media, and Blogs. -2009.

15. [Electronic resource]. - Available from: hbr.harvardbusiness.org (October 2014).

16. Hulme David, Arun Thankom. Microfinance. - 2009.

17. Investing in Development. UN Millennium Project. - September 2014.

18. Kaushik A. Web Analytics 2.0: The Art of Online Accountability and Science of Customer Centricity, 2009.

19. Kola Forcim. Microcredit contribution on social wellbeing. - "LAPLAMBERT Academic Publishing".//[Electronic resource]. - Available from: AMAZON.com. - ISBN-13: 978-3843354110, Germany, 15 September 2010.

20. Mayzlin D. Promotional chat on the Internet.//Marketing Science. - 2006. - 25 (2), 155-163.

21. Microfinance Market Outlook 2014. - September 2014.

22. Strauss J. \& Frost R. E-Marketing, $7^{\text {th }}$ Edition. -2013.

23. Sundaresan Suresh. Microfinance, Emerging Trends and Challenges. - 2008.

24. Ward E. \& French G. Ultimate Guide to Link Building: How to Build Backlinks, Authority and Credibility for Your Website, and Increase Click Traffic and Search Ranking. - 2013.

25. Wright and N. Microfinance Systems: Designing Quality Financial Services for the Poor. - The University Press, Dhaka, 2000.

26. [Electronic resource]. - Available from: http://www.ifad.org (September 2014).

27. [Electronic resource]. - Available from: http://www.microjournal.com (October 2014).

28. [Electronic resource]. - Available from: http://www.mixmarket.org (September 2014).

29. [Electronic resource]. - Available from: http://www.responsAbility.com/webcast (October 2014).

30. [Electronic resource]. - Available from: http://www.worldbank.org (September 2014).

31. Yunus and Muhammad. Creating a World without Poverty: Social Business and the Future of Capitalism. Public Affairs, 2008.

32. Source: Data collected by the survey. - October 2014. 